\title{
Adsorption of Albumin on Silica Surfaces Modified by Silver and Copper Nanoparticles
}

\author{
Prity Kumari and Peter Majewski \\ School of Advanced Manufacturing and Mechanical Engineering, Mawson Institute, University of South Australia, Mawson Lakes, \\ Adelaide, SA 5095, Australia \\ Correspondence should be addressed to Peter Majewski; peter.majewski@unisa.edu.au
}

Received 30 January 2013; Revised 27 May 2013; Accepted 27 May 2013

Academic Editor: Mohamed Bououdina

Copyright (C) 2013 P. Kumari and P. Majewski. This is an open access article distributed under the Creative Commons Attribution License, which permits unrestricted use, distribution, and reproduction in any medium, provided the original work is properly cited.

\begin{abstract}
Silver and copper nanoparticles, respectively, were produced on glass slides via magnetron sputtering. The experiments show that with magnetron sputtering the size and concentration of the nanoparticles can be easily controlled via sputter time and plasma power. Silver nanoparticles grow much faster than copper nanoparticles, which also require higher plasma power for their synthesis. Exposed to albumin solution, the glass slides with silver nanoparticles clearly show a delay in albumin attachment compared to pure glass slides. Glass slides with copper nanoparticles show a slight attachment of albumin even after $3 \mathrm{~h}$ of exposure. However, the albumin concentration on the surface of the glass slides was much smaller compared to pure glass slides and did not increase within $24 \mathrm{~h}$.
\end{abstract}

\section{Introduction}

Infection as a result of bacteria attachment and biofilm formation on biomedical devices and implants is a major problem for the health system world wide [1]. One potential approach for reducing the use of antibiotics is the introduction of antimicrobial surface coatings. Various antimicrobial materials have been investigated to develop antibiofouling surface coatings that have the ability to prevent the attaching of proteins, bacteria, or marine organisms [2-9]. However, many of the developed anti-biofouling coatings have failed in medical applications due to bacteria mutation and their ability to develop antibacterial resistance or because the employed anti-biofouling components are highly toxic and, therefore, not employable in medicine [10-12].

In recent times, the use of nanoparticles as antimicrobial agent is studied intensively. The most widely studied nanomaterial for this purpose is silver nanoparticles (AgNPs) and the antimicrobial [13-17], antiviral [18, 19], and even antifungal $[20,21]$ are studied in detail. AgNPs have efficient antimicrobial properties due to their extremely large surface area, which indicates that small AgNPs have better antimicrobial properties than larger particles [22]. AgNPs get attached to the cell membrane and can also penetrate the membrane and travel into the bacteria. Studies indicate that AgNPs interact with sulphur-containing proteins in the bacteria membrane which results in the loss of essential bacteria functions like respiration and permeability [22-25]. Other studies suggest that AgNPs initiate the formation of radicals that interact with the bacterial membrane causing cell death [16]. Copper nanoparticles (CuNPs) have also attracted interest for applications as anti-biofouling agent, due to their catalytic and electrocatalytic properties [26,27]. Although the antimicrobial effect of AgNPs has been studied widely, the attachment of proteins on surfaces coated with nanoparticles has been investigated to a much lesser extent [28], although it is known that proteins on surfaces can significantly accelerate bacterial attachment and biofilm formation [29]. Therefore, the prevention of protein attachment on surfaces and the investigation of the ability of nanoparticles to prevent this are well justified.

In this study, the attachment of albumin protein on surfaces coated with AgNPs and CuNPs versus time using matrix-assisted laser desorption/ionization mass spectrometry (MALDI-MS) is studied. A large number of different chemical (e.g., [16, 30]) and physical (e.g., [31]) methods have 
been developed to prepare metal nanoparticles. In this study, nanoparticles on glass slides were synthesized via magnetron sputtering and their growth as a function of sputter time is also studied.

\section{Experimental}

2.1. Magnetron Sputtering. Glass slides with a dimension of $24 \times 75 \mathrm{~mm}^{2}$ were used as substrates. Before sputtering, the substrates were cleaned with ethanol. For the deposition of copper and silver nanoparticles, copper and silver targets with a purity of $99.99 \%$ were used. After placing the substrates together with the grids for transmission electron microscopy (TEM, Philips CM 200 transmission electron microscope) into the sputter chamber, the chamber was evacuated down to $3 \times 10^{-3}$ mbar and subsequently the Argon plasma was ignited. Copper nanoparticles were produced at room temperature using a plasma power of $50 \mathrm{~W}$ and sputter times of 10 and $20 \mathrm{~s}$, respectively. Silver nanoparticles were produced at room temperature using a plasma power of $18 \mathrm{~W}$ and deposition times of 2,5 , and 10 seconds, respectively.

2.2. Albumin Attachment. Mouse serum albumin (MSA) was used for the experiments (Aldrich, nitrogen content $14.8 \%$, fraction V (9048-46-8), EC no. 232-936-2, A-3139, lot $083 \mathrm{~K} 7607$, desiccate). An amount of $10.03 \mu \mathrm{g}$ of MSA powder was dissolved in $5 \mathrm{~mL}$ of milli-q water in a vial and stored at $+8^{\circ} \mathrm{C}$ for further use. Before the analyses, a drop of the albumin solution was applied onto the samples by a syringe. The samples were placed into a Petri dish and covered with a wet cloth to avoid drying of the albumin solution during the adsorption process, as drying of the droplet would result in deposited, but not bonded, albumin on the surface, which would artificially alter the MALDI-MS results.

2.3. Matrix-Assisted Laser Desorption/Ionization Mass Spectrometry (MALDI-MS). For MALDI-MS analysis was performed using a Bruker Autoflex III MALDI MS/MS (Bruker, Germany).

2.4. Uv-Vis Spectroscopy. UV-Vis absorption spectra of the glass slides with deposited nanoparticles were obtained using Cary 5 UV-Vis spectrometer (Varian Australia Pty Ltd.).

\section{Results and Discussion}

3.1. UV-Vis Spectrometry. The UV-Vis spectra of the glass slide sputtered with silver for $5 \mathrm{~s}$ and copper for $10 \mathrm{~s}$, respectively, are shown in Figure 1. The spectrum of the glass slide sputtered with silver clearly shows an absorption band at $420 \mathrm{~nm}$ which verifies the presence of AgNPs on the surface of the glass slide [32]. The glass slides sputtered with copper exhibits an absorption at about $600 \mathrm{~nm}$ which gives evidence for the presence of CuNPs on the glass slide [33].

3.2. X-Ray Photon Spectroscopy (XPS). XPS analysis of the surfaces of the glass slides shows clear peaks for silver and copper, respectively. The sample sputtered with silver shows

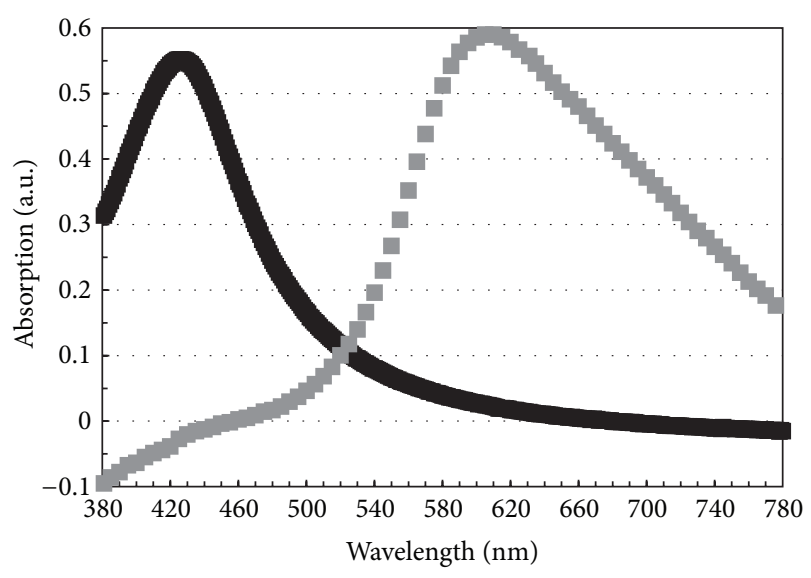

FIgURE 1: UV-Vis absorption spectra for glass slides with silver nanoparticles (black) and copper nanoparticles (grey).

a silver Ag 3d 3/2 and AG 3d 5/2 peaks (Figure 2). The high resolution XPS scan reveals that the AG $3 \mathrm{~d} 3 / 2$ peak can be split into a peak at a binding energy of $373.56 \mathrm{eV}$ and a peak at a binding energy of $374.64 \mathrm{eV}$ which gives evidence of the presence of ionic silver of $\mathrm{Ag}_{2} \mathrm{O}$ and metallic silver, respectively $[34,35]$. The AG $3 \mathrm{~d} 5 / 2$ peak can also be split into two peaks at binding energies of $367.56 \mathrm{eV}$ and $368.64 \mathrm{eV}$, respectively, also revealing the presence of $\mathrm{Ag}_{2} \mathrm{O}$ and metallic silver $[35,36]$. The presence of $\mathrm{Ag}_{2} \mathrm{O}$ is presumably due to partial surface oxidation of the AgNPs after deposition.

The high resolution XPS scan for copper shows two $\mathrm{Cu}$ 2 p $3 / 2$ peaks at binding energies of $932.45 \mathrm{eV}$ and $934.52 \mathrm{eV}$ which can be attributed to metallic copper and ionic copper of $\mathrm{CuO}$, respectively $[37,38]$ (Figure 3 ). The $\mathrm{Cu} 2 \mathrm{p} 1 / 2$ peak can also be split into two peaks at binding energies of $952.26 \mathrm{eV}$ and $953.77 \mathrm{eV}$ which also gives evidence for the presence of metallic copper and $\mathrm{CuO}$, respectively, on the surface of the sample $[39,40]$. The presence of $\mathrm{CuO}$ on the surface is presumably also due to partial oxidation of the CuNPs after deposition of the nanoparticles.

3.3. Transmission Electron Microscopy. The TEM images of the samples clearly show the presence of nanoparticles on the surface of the silica slides (Figures 4 to 8 ). It is obvious that with increasing sputter time the size of the nanoparticles increases. The AgNPs increase in size from between 1 and $10 \mathrm{~nm}$ to between 5 and $50 \mathrm{~nm}$ within 10 seconds at a plasma power of $18 \mathrm{~W}$. In addition, the shapes of the nanoparticles change from spherical (Figures 4 and 5) to irregular (Figure 6). In contrast, the CuNPs appear to grow much slower than the silver nanoparticles (Figures 7 and 8) and their size is still below about $5 \mathrm{~nm}$ even after sputter times of 20 seconds at much higher plasma power of $50 \mathrm{~W}$. At plasma powers below $50 \mathrm{~W}$, CuNPs could not be detected on the glass slides. The reason for this phenomenon is presumably the high melting temperature and ionization energy of copper compared to silver which influence the kinetics of grain growth during magnetron sputter deposition [41]. It also appears that with increasing sputter time, the 


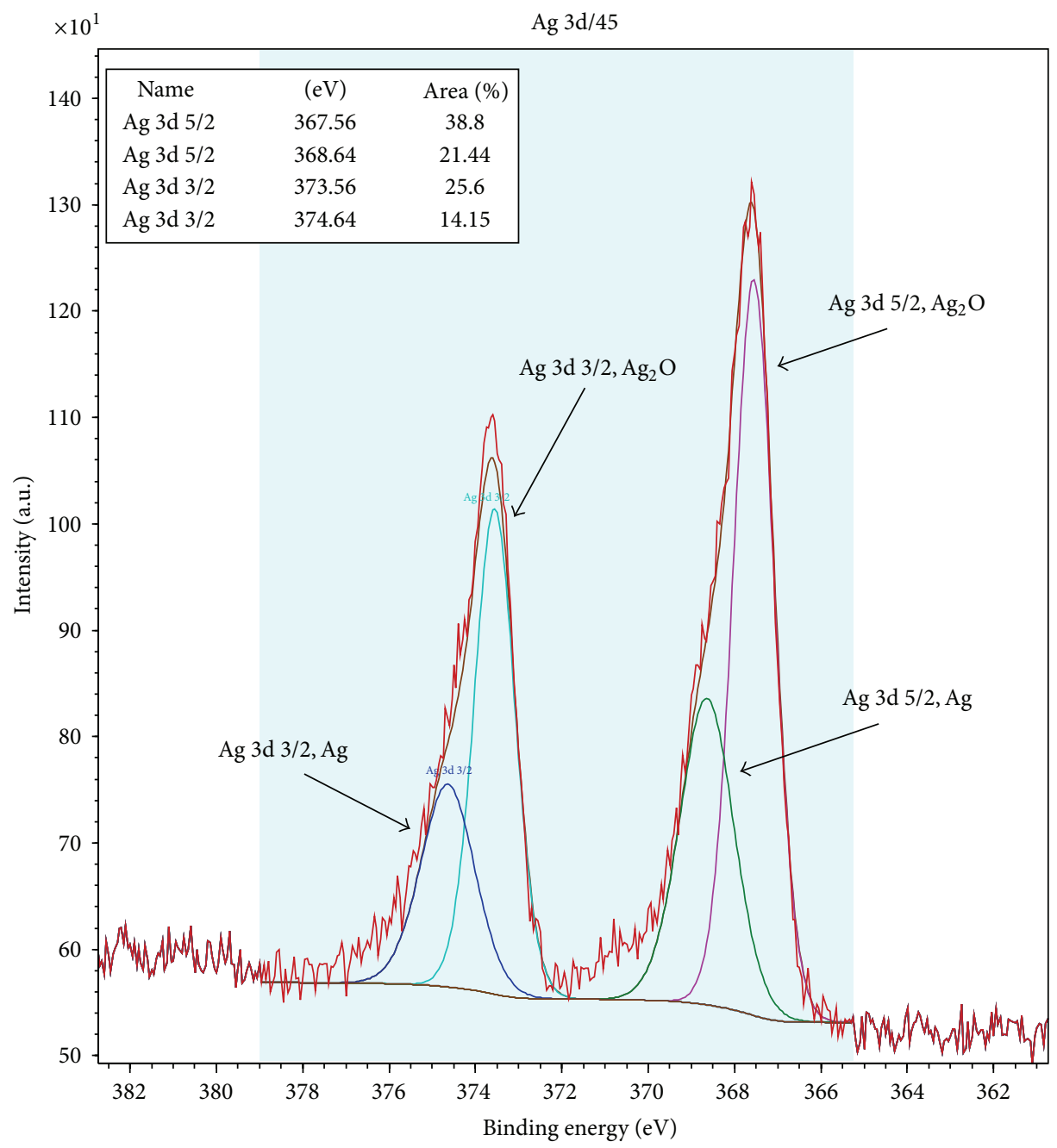

FIGURE 2: High resolution XPS spectrum of glass slide with silver nanoparticles.

size of the CuNPs does not increase, whereas the number of nanoparticles increases.

\subsection{Matrix-Assisted Laser Desorption/Ionization Mass Spec-} trometry (MALDI-MS). The MALDI MS analyses of the albumin adsorption experiments are shown in Figures 9, 10, and 11. After only three hours of exposure to the MSA solution, the MALDI-MS analysis of the pure silica sample clearly shows pronounced peaks at about $35000 \mathrm{~m} / z$ and $62000 \mathrm{~m} / z$. All these peaks can be attributed to albumin ${ }^{\text {about1+ }}$ and albumin $^{\text {about2+ }}$ peaks [42], although the peak at $62000 \mathrm{~m} / z$ is at slightly lower $m / z$ value than that reported in the literature [42]. This phenomenon may be due to the attachment of none complete albumin molecules. Minor peaks can be identified at about $14000 \mathrm{~m} / z, 22500 \mathrm{~m} / z$, and $28500 \mathrm{~m} / z$, which are not identified, but my be attributed to albumin ${ }^{n+}$ peaks with $2<n<4[43]$.

The samples sputtered with silver for $5 \mathrm{~s}$ do not show any related peaks after $3 \mathrm{~h}$ of exposure to the MSA solution. However, after $24 \mathrm{~h}$ of exposure the albumin ${ }^{1+}$ and albumin $^{2+}$ peaks are clearly visible besides peaks at
$28500 \mathrm{~m} / z, 22500 \mathrm{~m} / z$, and $14000 \mathrm{~m} / z$. This observation indicates that the adsorption of albumin on the surface with attached AgNPs is significantly delayed compared to the pure silica surface. However, after prolonged exposure, albumin is clearly adsorbed by the surface with AgNPs.

The samples containing CuNPs sputtered for $20 \mathrm{~s}$ show a very different result. Although albumin ${ }^{1+}$ and albumin ${ }^{2+}$ peaks are visible after $3 \mathrm{~h}$ and $24 \mathrm{~h}$, respectively, the peaks are significantly weaker compared to those on pure silica and silica with AgNPs at albumin exposure for $24 \mathrm{~h}$ and the peaks at $35000 \mathrm{~m} / z$ and $62000 \mathrm{~m} / z$ do not increase between 3 and $24 \mathrm{~h}$ of exposure to albumin. The reason for this phenomenon is believed to be caused by the fact that CuNPs are significantly smaller than AgNPs, so that the larger albumin molecule (about 8 to $10 \mathrm{~nm} \mathrm{[44])} \mathrm{is} \mathrm{able} \mathrm{to} \mathrm{attach}$ to the silica surface to some extent by bridging the smaller nanoparticle. Nevertheless, as the adsorption of albumin does not increase within $24 \mathrm{~h}$ of exposure, it is believed that CuNPs have the ability to prevent further adsorption of albumin. However, the underlying physical and chemical phenomena that delays albumin attachment is yet to be clarified and will be presented later. 


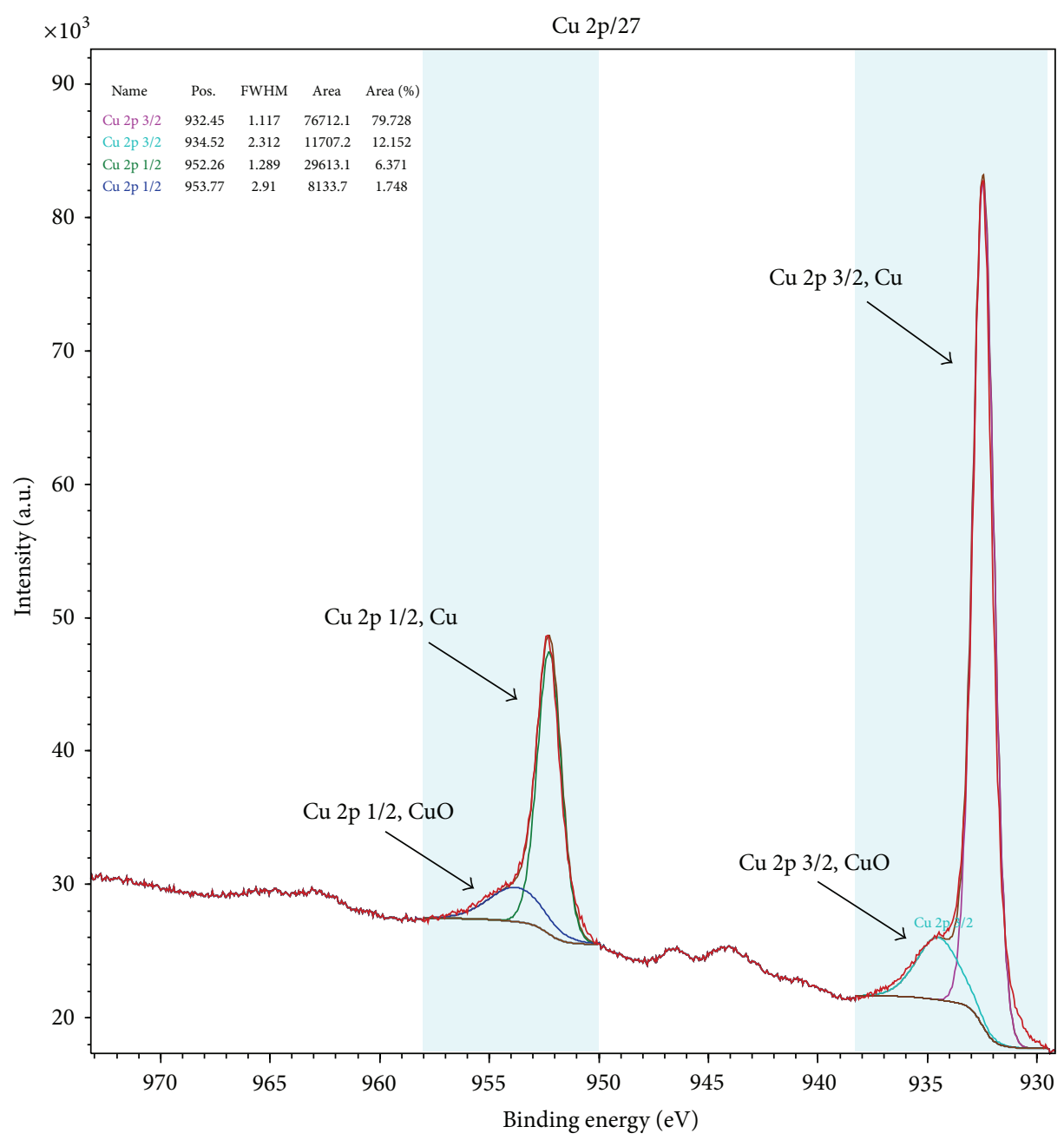

FIGURE 3: High resolution XPS spectrum of glass slide with copper nanoparticles.

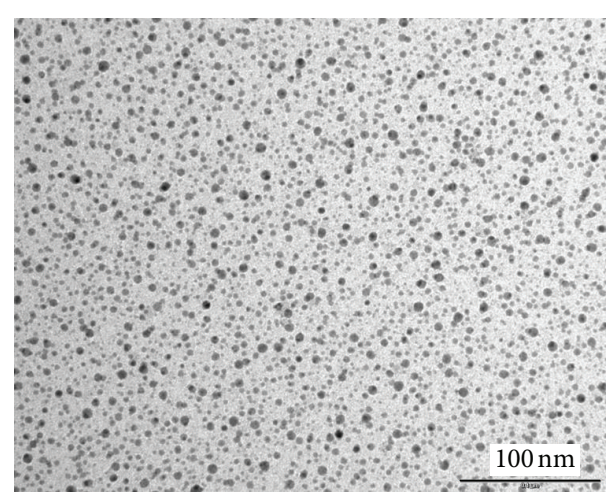

FIGURE 4: Ag nanoparticles sputtered on silica for 2 seconds.

\section{Conclusion}

Magnetron sputtering appears to be a very potent technology to produce nanoparticles on surfaces. Size and concentration of nanoparticles can easily be controlled by plasma energy and sputter time as shown in this study.

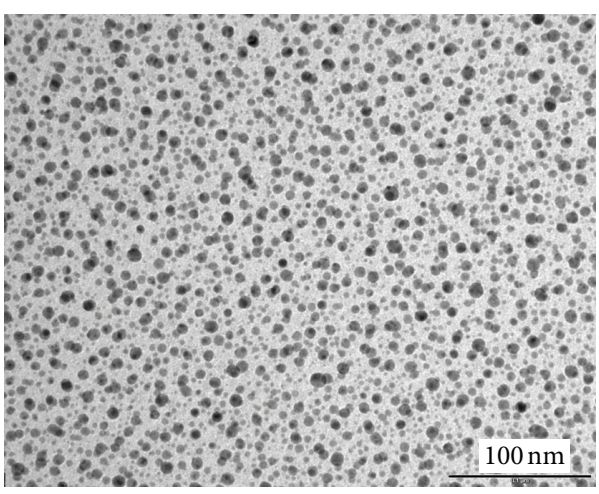

FIGURE 5: Ag nanoparticles sputtered on silica for 5 seconds.

The experiments conducted here also show that AgNPs and CuNPs have the capacity to clearly delay the attachment of albumin of the coated surfaces. However, in case of AgNPs, it is obvious that attachment of albumin cannot be completely prevented after prolonged exposure to albumin solution for $24 \mathrm{~h}$. In case of CuNPs, although a very minor 


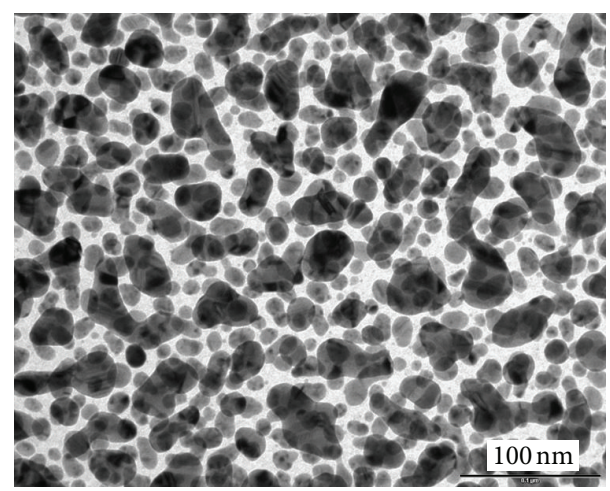

FIgURE 6: Ag nanoparticles sputtered on silica for 10 seconds.

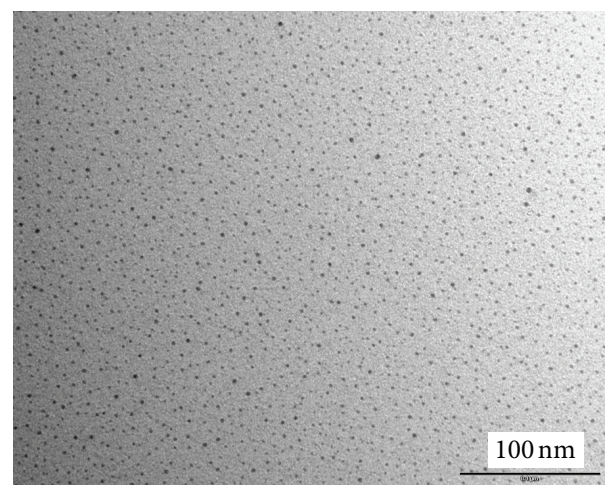

FIgURE 7: Cu nanoparticles sputtered on silica for 10 seconds.

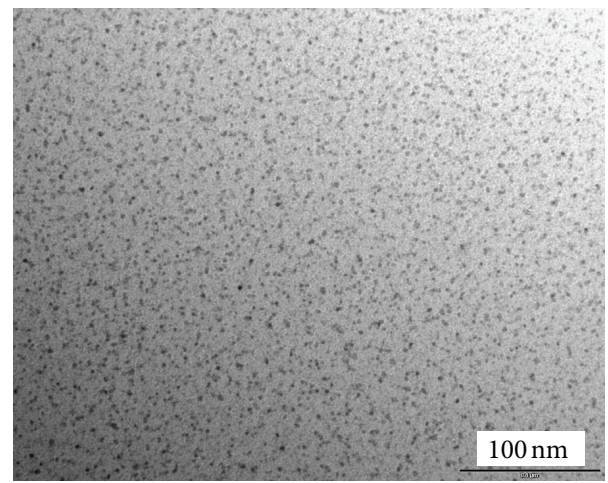

FIGURE 8: Cu nanoparticles sputtered on silica for 20 seconds.

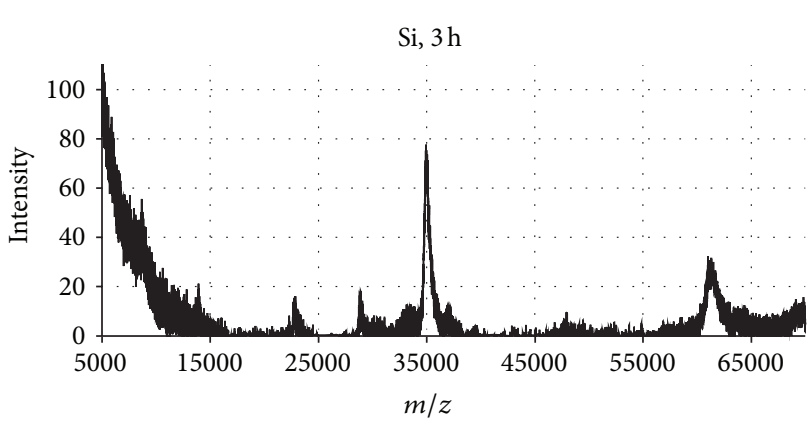

Figure 9: MALDI-MS spectrum of pure silica after $3 \mathrm{~h}$ of contact with MSA solution.

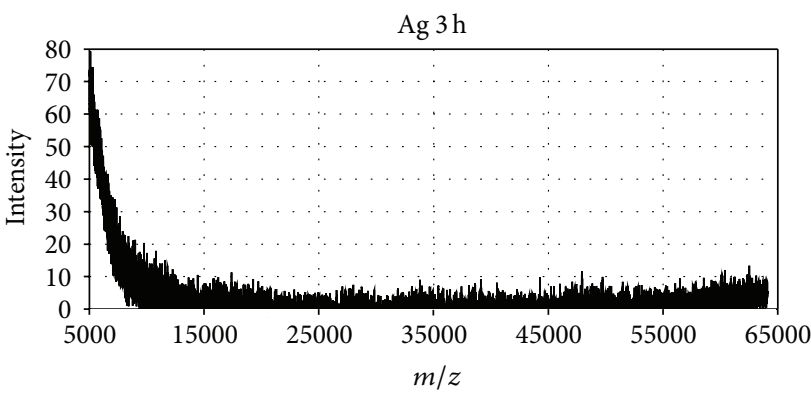

(a)

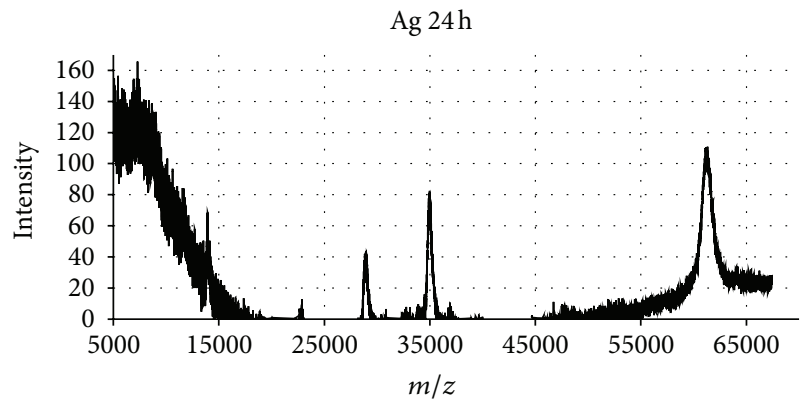

(b)

FIgURE 10: MALDI-MS spectrum of silica with Ag nanoparticles after $3 \mathrm{~h}$ (a) and $24 \mathrm{~h}$ (b), respectively, of contact with MSA solution.

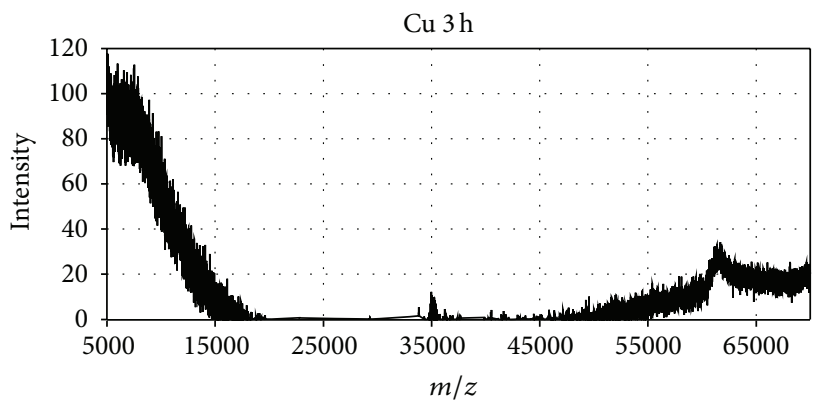

(a)

$\mathrm{Cu} 24 \mathrm{~h}$

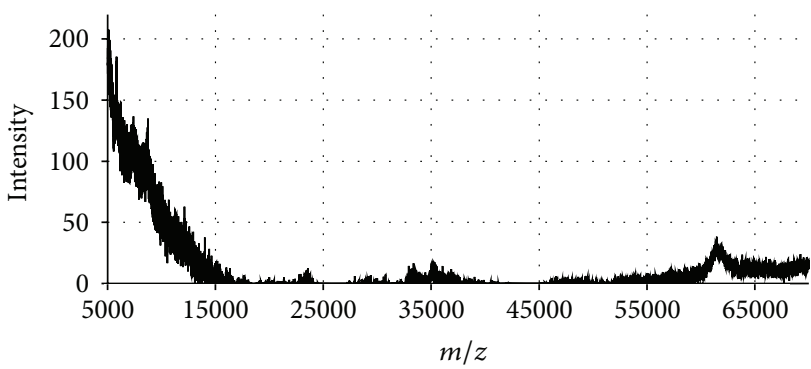

(b)

FIGURE 11: MALDI-MS spectrum of silica with $\mathrm{Cu}$ nanoparticles after $3 \mathrm{~h}$ (a) and $24 \mathrm{~h}$ (b), respectively, of contact with MSA solution. 
albumin attachment is detectable after exposure for only $3 \mathrm{~h}$, no further increase of albumin attachment was observed within $24 \mathrm{~h}$ of exposure. This observation may indicate that the size of the nanoparticles may play a role in the albumin attachment. Very small nanoparticles like those in case of the CuNPs ( 1 to $5 \mathrm{~nm}$ ) may not completely prevent albumin attachment, as the albumin molecule has a size of about 8 to $10 \mathrm{~nm}$, whereas nanoparticles in the size range of 10 to $20 \mathrm{~nm}$ like AgNPs observed on the glass slides are able to prevent albumin attachment.

The fact that albumin attachment can be delayed by coatings of AgNPs and CuNPs is of some significance, as biomedical tools are often used only once after removing them from sterile packaging and are then used only for short time, for example, during surgery. If protein attachment can be prevented during that time period, as shown for surfaces coated with AgNPs, the chance of infection is clearly reduced.

\section{Conflict of Interests}

The authors declare that they have no conflict of interests.

\section{References}

[1] D. Mack, H. Rohde, L. G. Harris, A. P. Davies, M. A. Horstkotte, and J. K.-M. Knobloch, "Biofilm formation in medical devicerelated infection," International Journal of Artificial Organs, vol. 29, no. 4, pp. 343-359, 2006.

[2] S. Noimark, C. W. Dunnill, M. Wilson, and I. P. Parkin, "The role of surfaces in catheter-associated infections," Chemical Society Reviews, vol. 38, no. 12, pp. 3435-3448, 2009.

[3] K. Vasilev, J. Cook, and H. J. Griesser, "Antibacterial surfaces for biomedical devices," Expert Review of Medical Devices, vol. 6, no. 5, pp. 553-567, 2009.

[4] J. C. Tiller, C.-J. Liao, K. Lewis, and A. M. Klibanov, "Designing surfaces that kill bacteria on contact," Proceedings of the National Academy of Sciences of the United States of America, vol. 98, no. 11, pp. 5981-5985, 2001.

[5] M. S. Kim, G. Khang, and H. B. Lee, "Gradient polymer surfaces for biomedical applications," Progress in Polymer Science, vol. 33, no. 1, pp. 138-164, 2008.

[6] I. Banerjee, R. C. Pangule, and R. S. Kane, "Antifouling coatings: recent developments in the design of surfaces that prevent fouling by proteins, bacteria, and marine organisms," Advanced Materials, vol. 23, no. 6, pp. 690-718, 2011.

[7] F. Costa, I. F. Carvalho, R. C. Montelaro, P. Gomes, and M. C. L. Martins, "Covalent immobilization of antimicrobial peptides (AMPs) onto biomaterial surfaces," Acta Biomaterialia, vol. 7, no. 4, pp. 1431-1440, 2011.

[8] W. C. E. Schofield and J. P. S. Badyal, "A substrate-independent approach for bactericidal surfaces," ACS Applied Materials and Interfaces, vol. 1, no. 12, pp. 2763-2767, 2009.

[9] A. Simchi, E. Tamjid, F. Pishbin, and A. R. Boccaccini, "Recent progress in inorganic and composite coatings with bactericidal capability for orthopaedic applications," Nanomedicine, vol. 7, no. 1, pp. 22-39, 2011.

[10] H. de Lencastre, D. Oliveira, and A. Tomasz, "Antibiotic resistant Staphylococcus aureus: a paradigm of adaptive power," Current Opinion in Microbiology, vol. 10, no. 5, pp. 428-435, 2007.
[11] H. Nikaido, "Multidrug resistance in bacteria," Annual Review of Biochemistry, vol. 78, pp. 119-146, 2009.

[12] I. M. Gould, "Antibiotics, skin and soft tissue infection and meticillin-resistant Staphylococcus aureus: cause and effect," International Journal of Antimicrobial Agents, vol. 34, supplement 1, pp. S8-S11, 2009.

[13] M. L. W. Knetsch and L. H. Koole, "New strategies in the development of antimicrobial coatings: the example of increasing usage of silver and silver nanoparticles," Polymers, vol. 3, no. 1, pp. 340-366, 2011.

[14] K. Senior, S. Muller, V. J. Schacht, and M. Bunge, "Antimicrobial precious-metal nanoparticles and their use in novel materials," Recent Patents on Food, Nutrition \& Agriculture, vol. 4, pp. 200 209, 2012.

[15] V. K. Sharma, R. A. Yngard, and Y. Lin, "Silver nanoparticles: green synthesis and their antimicrobial activities," Advances in Colloid and Interface Science, vol. 145, no. 1-2, pp. 83-96, 2009.

[16] J. S. Kim, E. Kuk, K. N. Yu et al., "Antimicrobial effects of silver nanoparticles," Nanomedicine, vol. 3, no. 1, pp. 95-101, 2007.

[17] M. Rai, A. Yadav, and A. Gade, "Silver nanoparticles as a new generation of antimicrobials," Biotechnology Advances, vol. 27, no. 1, pp. 76-83, 2009.

[18] S. Galdiero, A. Falanga, M. Vitiello, M. Cantisani, V. Marra, and M. Galdiero, "Silver nanoparticles as potential antiviral agents," Molecules, vol. 16, no. 10, pp. 8894-8918, 2011.

[19] H. H. Lara, E. N. Garza-Treviño, L. Ixtepan-Turrent, and D. K. Singh, "Silver nanoparticles are broad-spectrum bactericidal and virucidal compounds," Journal of Nanobiotechnology, vol. 9, article 30, 2011.

[20] A. Panáček, M. Kolár, R. Večeřová et al., "Antifungal activity of silver nanoparticles against Candida spp," Biomaterials, vol. 30, no. 31, pp. 6333-6340, 2009.

[21] L. S. Acosta-Torres, I. Mendieta, R. E. Nuñez-Anita, M. CajeroJuárez, and V. M. Castaño, "Cytocompatible antifungal acrylic resin containing silver nanoparticles for dentures," Internat $J$ Nanomedicine, vol. 7, pp. 4777-4786, 2012.

[22] J. R. Morones, J. L. Elechiguerra, A. Camacho et al., "The bactericidal effect of silver nanoparticles," Nanotechnology, vol. 16, no. 10, pp. 2346-2353, 2005.

[23] Q. L. Feng, J. Wu, G. Q. Chen, F. Z. Cui, T. N. Kim, and J. Q. Kim, "A mechanistic study of the antibacterial effect of silver ions on Escherichia coli and Staphylococcus aureus," Journal of Biomedical Materials, vol. 52, pp. 662-668, 2000.

[24] I. Sondi and B. Salopek-Sondi, "Silver nanoparticles as antimicrobial agent: a case study on E. coli as a model for Gramnegative bacteria," Journal of Colloid and Interface Science, vol. 275, no. 1, pp. 177-182, 2004.

[25] H. Y. Song, K. K. Ko, L. H. Oh, and B. T. Lee, "Fabrication of silver nanoparticles and their antimicrobial mechanisms," European Cells and Materials, vol. 11, pp. 58-60, 2006.

[26] I.-W. Shim, W.-T. Noh, J. Kwon, J. Y. Cho, K.-S. Kim, and D. H. Kang, "Preparation of copper nanoparticles in cellulose acetate polymer and the reaction chemistry of copper complexes in the polymer," Bulletin of the Korean Chemical Society, vol. 23, no. 4, pp. 563-568, 2002.

[27] H. H. Huang, F. Q. Yan, Y. M. Kek et al., "Synthesis, characterization, and nonlinear optical properties of copper nanoparticles," Langmuir, vol. 13, no. 2, pp. 172-179, 1997.

[28] C. Latasa, C. Solano, J. R. Penadés, and I. Lasa, "Biofilmassociated proteins," Comptes Rendus, vol. 329 , no. 11, pp. 849857, 2006. 
[29] Y. Schmitt, H. Hähl, C. Gilow et al., "Structural evolution of protein-biofilms: simulations and experiments," Biomicrofluidics, vol. 4, no. 3, Article ID 032201, 2010.

[30] J. Kimling, M. Maier, B. Okenve, V. Kotaidis, H. Ballot, and A. Plech, "Turkevich method for gold nanoparticle synthesis revisited," Journal of Physical Chemistry B, vol. 110, no. 32, pp. 15700-15707, 2006.

[31] P. Wagener, S. Barcikowski, and N. Baersch, "Fabrication of nanoparticles and nanomaterials using laser ablation in liquids," Photonik International, vol. 1, pp. 20-23, 2011.

[32] V. Amendola, O. M. Bakr, and F. Stellacci, "A study of the surface plasmon resonance of silver nanoparticles by the discrete dipole approximation method: effect of shape, size, structure, and assembly," Plasmonics, vol. 5, no. 1, pp. 85-97, 2010.

[33] P. K. Khanna, S. Gaikwad, P. V. Adhyapak, N. Singh, and R. Marimuthu, "Synthesis and characterization of copper nanoparticles," Materials Letters, vol. 61, no. 25, pp. 4711-4714, 2007.

[34] Y. Liu, R. G. Jordan, and S. L. Qiu, "Electronic structures of ordered Ag-Mg alloys," Physical Review B, vol. 49, no. 7, pp. 44784484, 1994.

[35] L. H. Tjeng, M. B. J. Meinders, J. Van Elp, J. Ghijsen, G. A. Sawatzky, and R. L. Johnson, "Electronic structure of $\mathrm{Ag}_{2} \mathrm{O}$," Physical Review B, vol. 41, no. 5, pp. 3190-3199, 1990.

[36] M. P. Seah, G. C. Smith, and M. T. Anthony, "AES. Energy calibration of electron spectrometers. I. An absolute, traceable energy calibration and the provision of atomic reference line energies," Surface and Interface Analysis, vol. 15, no. 5, pp. 293308, 1990.

[37] M. P. Seah, I. S. Gilmore, and G. Beamson, "XPS: binding energy calibration of electron spectrometers 5-Re-evaluation of the reference energies," Surface and Interface Analysis, vol. 26, no. 9, pp. 642-649, 1998.

[38] F. Parmigiani, G. Pacchioni, F. Illas, and P. S. Bagus, "Studies of the $\mathrm{CuO}$ bond in cupric oxide by X-ray photoelectron spectroscopy and ab initio electronic structure models," Journal of Electron Spectroscopy and Related Phenomena, vol. 59, no. 3, pp. 255-269, 1992.

[39] A. N. Mansour, "Gold $M g \mathrm{~K}_{\alpha}$ XPS spectra from the physical electronics model 5400 spectrometer," Surface Science Spectra, vol. 3, no. 3, 5 pages, 1994.

[40] J. G. Jolley, G. G. Geesey, M. R. Haukins, R. B. Write, and P. L. Wichlacz, "Auger electron and X-ray photoelectron spectroscopic study of the biocorrosion of copper by alginic acid polysaccharide," Applied Surface Science, vol. 37, no. 4, pp. 469480, 1989.

[41] J. A. Thornton, "The microstructure of sputter-deposited coatings," Journal of Vacuum Science \& Technology A, vol. 4, pp. 3059-3065, 1986.

[42] R. Spares, C. Franco, E. Pires et al., "Mass spectrometry and animal science: protein identification strategies and particularities of farm animal species," Journal of Proteomics, vol. 75, pp. 41904206, 2012.

[43] C. Dass, Principles and Practice of Biological Mass Spectrometry, John Wiley, New York, USA, 2001.

[44] M. A. Kiselev, I. A. Gryzunov, G. E. Dobretsov, and M. N. Komarova, "Size of a human serum albumin molecule in solution," Biofizika, vol. 46, no. 3, pp. 423-427, 2001. 

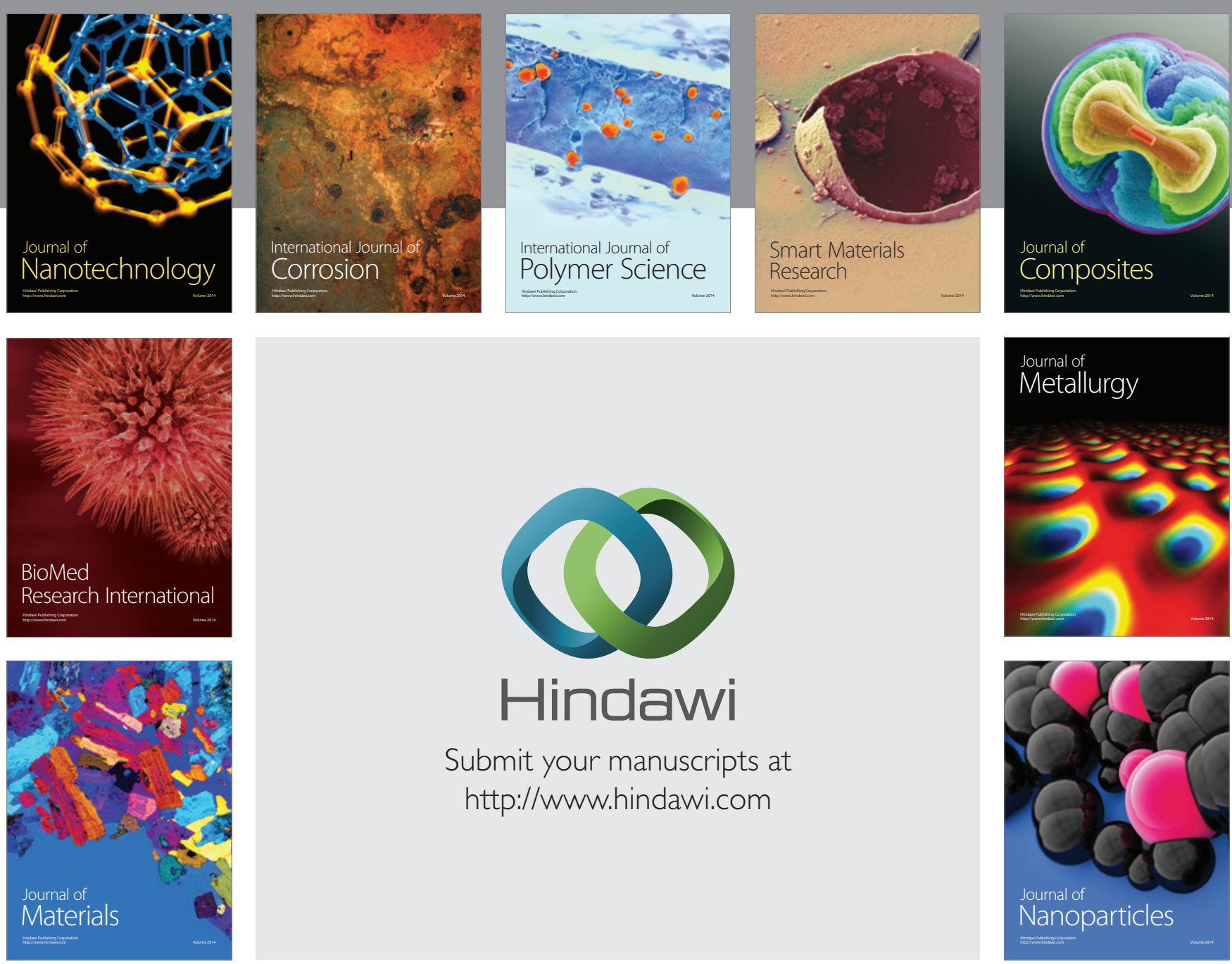

Submit your manuscripts at http://www.hindawi.com
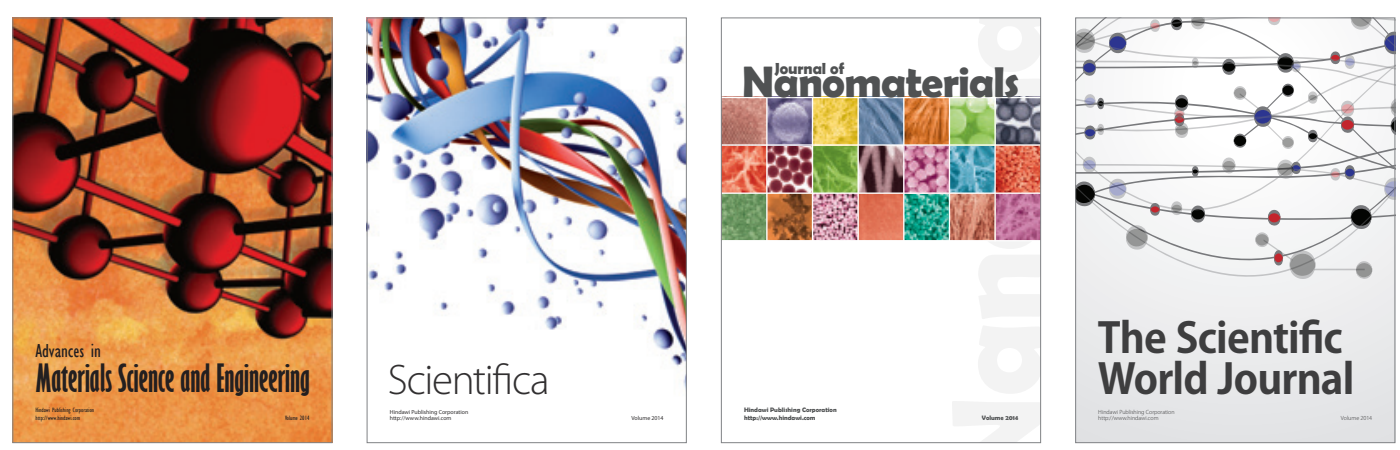

\section{The Scientific World Journal}
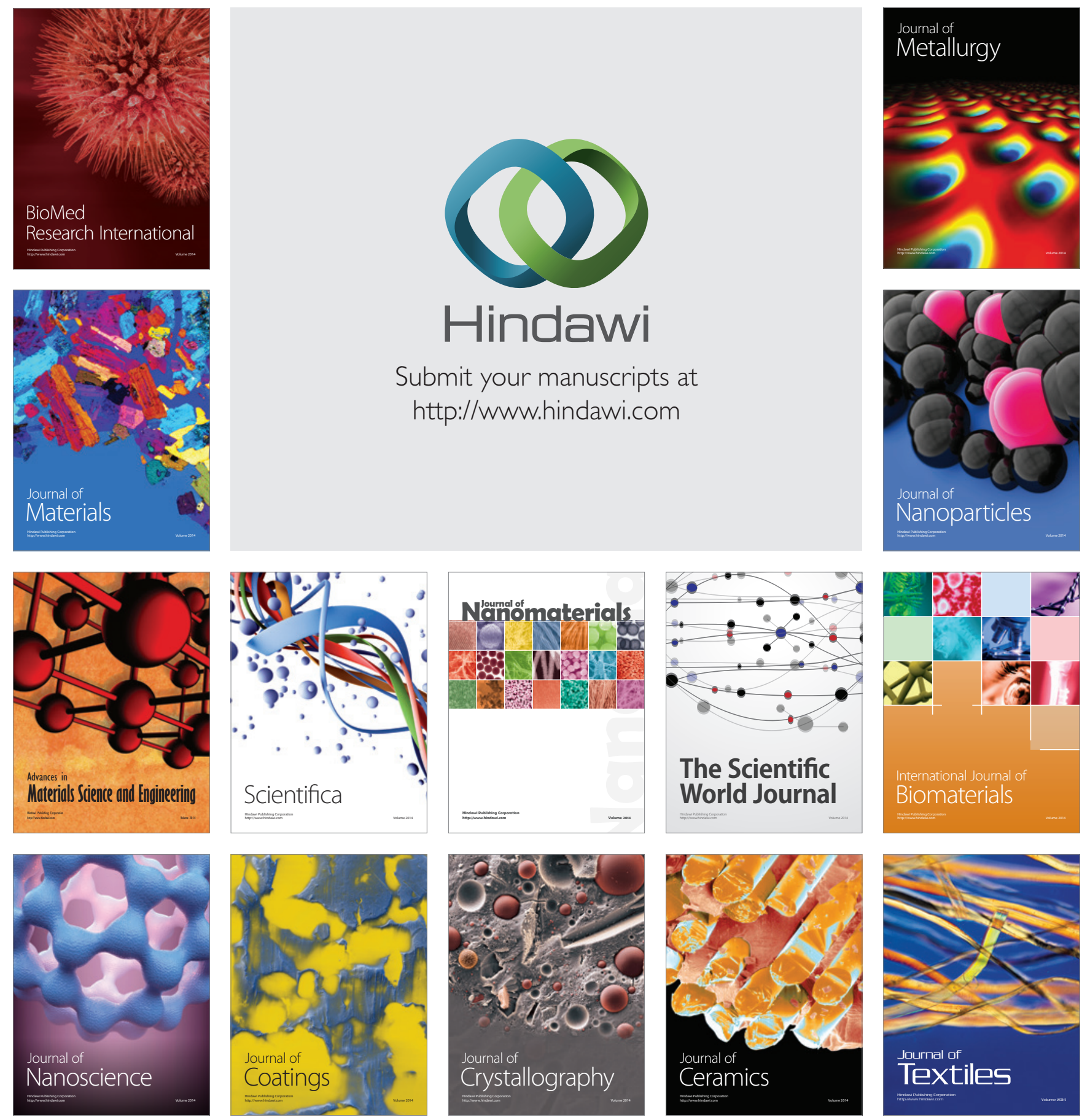